\title{
WHAT IS THE ROLE BODY SWAY DEVIATION AND BODY SWAY VELOCITY PLAY IN POSTURAL STABILITY IN OLDER ADULTS?
}

\begin{abstract}
Jitka Jančová V̌setečkován ${ }^{1,2}$, Nicholas Drey ${ }^{2}$
Charles University in Prague, Faculty of Physical Education and Sport Science, Czech Republic: Department of Sport Medicine and Adapted Physical Education ${ }^{1}$; School of Health Sciences, City University London, United Kingdom²

Summary: This cross sectional study focused on how Postural Stability (PS) indicators: body sway deviation (BSD) and body sway velocity (BSV), change with age and their association with levels of social and physical activity. Observational study: 80 older adults (aged: 60-96) were purposefully recruited from two sources: the University of the Third Age (TAU) $(n=35)$ and a residential care home $(\mathrm{CH})(\mathrm{n}=45)$. Differences in the indicators of PS, approximated through Centre of Pressure (COP) measurements, were assessed by the Romberg Stance Test (Test A) subsequently repeated on $10 \mathrm{~cm}$ foam surface (Test B), using a Kistler ${ }^{\circledR}$ Dynamometric Platform. The RCH Group was older, had higher BMI and was less socially and physically active, showed more body sway in all indicators compared to TAU group. For all participants body sway velocity (BSV) was significantly correlated with age. The strength of correlation of body sway deviation (BSD) with age was also significant but not as strong. The findings indicate in line with previous studies that deterioration in BSV is associated with poor PS more than deterioration in BSD.
\end{abstract}

Key words: Body sway deviation (BSD); Body sway velocity (BSV); Postural stability (PS); Ageing; Platform stabilometry; Centre of pressure (COP)

\section{Introduction}

Ageing is affected by many physiological and pathological variables such as genes, lifestyle, and chronic disease, which interact in multiple ways, influencing the manner in which aging occurs (1). Age-related deterioration in Postural stability (PS) is often reported as the major determinant of falls and fracture risk in older adult $(2,3)$. Falls are a widespread cause of accidents and injury in the older adults, reported to impact hugely on health care costs (4). Unintentional injuries were reported to be the fifth leading cause of death where falls in older adults account for two thirds of these deaths (5). The majority of older adults who have fallen experienced psychological as well as physical harm (6). In community-living older people, the prevalence rates for fear of falling range from $20-85 \%$ (7), and from $15-55 \%$ is associated with avoidance of physical activity (7). When lacking physical activity older people are more likely to develop severe muscle atrophy, resulting often in Sarcopenia $(8,9)$ and a progressive substitution of muscle fibres by connective tissues (10). This affects muscle strength, flexibility, coordination and may result in an overall deterioration of PS (11), highly increasing the overall risk of falling (12), hospitalization and many other (physical as well as psychological) complications (13).

Postural Stability (PS) was defined as an ability to maintain the body's Centre of Gravity (COG) or Centre of Mass
(COM) over its Base of Support whether this base is stationary or moving $(1,12,14-17)$. Control of body sway (BS) during quiet standing is achieved physiologically by using feedback and feed forward mechanisms when responding to perturbations of stability (18). Postural Stability involves two subsystems $(19,20)$ : the passive subsystem including the skeleton and ligaments and the active subsystem which is a dynamic process set by muscle co-contraction, both reported to be influenced by age-related processes $(19,20)$.

In order to reduce falls and target an appropriate intervention, PS needs to be monitored. Several types of measurement have been developed to approximate PS. Some are balance tests; others are balance or BS measuring devices. A stabilometric platform is often used to measure BS through Centre of Pressure (COP) recording which is further divided into several indicators. These indicators include: Anterior/Posterior Body Sway Deviation (A/P BSD), Medial/ Lateral Body Sway Deviation (M/L BSD), Anterior/Posterior Body Sway Velocity (A/P BSV), Medial/Lateral Body Sway Velocity (M/L BSV) and Total Body Sway Area (TBSA), are considered as a reliable measure of BS $(12,16,21,22)$.

There is general consensus that age-related changes play an important role in BS, reported as greater in older people (over 60) than in younger adults $(1,9,23,24)(23)$. Some authors were focused on $\mathrm{BS}$ in both directions $(\mathrm{A} / \mathrm{P}$ and $\mathrm{M} / \mathrm{L}$ ) and reported that $\mathrm{A} / \mathrm{P} \mathrm{BS}$ was up to $52 \%$ greater in those aged $70-80$ years than in those aged $30-39$ (25), and that 
Medial-Lateral (M/L) BS control was most compromised in people at risk of falls (23). But little has been published on Body Sway Deviation (BSD) and Body Sway Velocity (BSV) in relation to calendar age and the extent to which they report on BS changes. For these reasons this observational study focuses on static PS approximated by 5 BS indicators through platform stabilometry measurements in two groups of older people, purposefully selected in relation to the level of self-reported adherence to social and physical activities, measured by a questionnaire previously used and validated by Tumova (26) in the Czech Republic, in two different tests of quiet standing. The aims were as follows:

- To observe and compare the Postural stability (PS) approximated by 5 Body sway (BS) indicators - in two tests of quiet standing in two purposefully selected groups (University of the Third Age group and Care Home group) of participants; in relation to their adherence to social and physical activities.

- To observe to what extent indicators of BS assess the PS measured on the Kistler's platform and use correlations to compare Body Sway Velocity (BSV) and Body Sway Deviation (BSD) relationship to calendar age.

\section{Material and Methods}

\section{Participants}

Eighty older adults (age range 60-96) volunteered for this observational study and were purposefully recruited through two different routes. One advertisement (Jan $2005-$ Jan 2007) was placed at Charles University and participants were recruited through the University of the Third Age program, and the second advertisement (Jan 2001 - Jan 2005) was placed in Residential Care Homes in Prague. These two groups were purposefully selected. Differences in physical and social activities were anticipated already at the baseline. We aimed to get as vigorous participants as we could and all the participants had to be able to accomplish the PS testing without help (see inclusion/exclusion criteria below).

- TAU group (University of the Third Age): $\mathrm{n}=27$; 23 women, $6 \mathrm{men} ; M_{\text {age }} 66.6 \pm 5.1$ years $(\min =57.5)$ $\max =75.8)$

- RCH group (Residential Care Home): $\mathrm{n}=53$; 42 women, $11 \mathrm{men} ; M_{\text {age }} 82.9 \pm 6.1$ years $(\min =71.6 / \max =96)$

\section{Inclusion / exclusion criteria}

Participants from both groups were included in the study if: they were able to complete PS testing (without help), gave informed consent and completed an administered questionnaire (see below). Participants were excluded if: they were unable to complete PS testing and needed help of another person, self-reported cerebrovascular, cardiac or neurological disease, were taking regular medication (having known impact on dizziness) or taking more than 3 drugs (by which way we tried to avoid heavy drug interactions), or have self-reported osteoporosis and/or osteoarthritis and had BMI $<23$ or $>33$. Most of our participants were able to complete the testing and if they were poly-morbid and reported some of the above mentioned conditions they were also taking more than 3 drugs which excluded them from the sample in one or the other way. We are also aware that the mean age of participants is not easily comparable but this has been addressed to some extent in data analysis and it is also addressed in limitations of this study.

\section{Materials and Procedure}

1. Social and physical activity levels and falls in previous years were assessed using a questionnaire, standardized and validated by Tumova (26). Questionnaires were administered to both groups and focused on previous and current levels of physical as well as social activity, self reported falls in the past 4 years with reasons why these occurred, and medication used regularly and occasionally. Participants were completing questionnaire individually. Answers to these questionnaires were used to help to interpret results from simultaneous PS measurements and identify participants who were less socially active and had lower levels of regular physical activity.

2. Height and weight (from which BMI was calculated) were collected.

3. PS was measured on 3D dynamometric Kistler® Platform 9287B in all participants. Participants stood upright and barefoot on the platform. Participants were asked to stand on the force plate with their feet positioned comfortably and arms at their sides, head in normal forward-facing position and eyes focused on a stationary target located $1.5 \mathrm{~m}$ away at individual eye-height. Each participant performed a 30 second standing test with 60 second rest to minimize any effects due to fatigue (21). The tests of Quiet Standing used in present study were as follows:

Test A - Double Narrow Stance Eyes Open (DNSEO) known as well as parallel narrow or Romberg stance EO (15, 16, 22). Test B - Double Narrow Stance Eyes Open (DNSEO) identical with Test A but performed on 10 thick foam plastic support. Typical for this type of stance is that proprioception is limited. This type of test is considered more difficult when compared to Test $A(26,27)$. In each test the following indicators were measured:

\begin{tabular}{|l|c|}
\hline Indicators & Values \\
\hline $\begin{array}{l}\text { Medial/Lateral Body Sway deviations } \\
\text { (M/L BSD) }\end{array}$ & {$[\mathrm{mm}]$} \\
\hline $\begin{array}{l}\text { Anterior/Posterior Body Sway deviations } \\
\text { (A/P BSD) }\end{array}$ & {$[\mathrm{mm}]$} \\
\hline $\begin{array}{l}\text { Medial/Lateral Body Sway velocity } \\
\text { (M/L BSV) }\end{array}$ & {$[\mathrm{mm} / \mathrm{sec}]$} \\
\hline $\begin{array}{l}\text { Anterior/Posterior Body Sway velocity } \\
\text { (A/P BSV) }\end{array}$ & {$[\mathrm{mm} / \mathrm{sec}]$} \\
\hline Total Body Sway Area (TBSA) & {$\left[\mathrm{mm}{ }^{2}\right]$} \\
\hline
\end{tabular}




\section{Data analysis}

Coordinates collected through the Kistler ${ }^{\circledR}$ platform measurement were entered into program software created for the Kistler ${ }^{\circledR}$ Platform by Boswart (28). From the recorded Centre of Pressure (COP) trajectory were computed values in Anterior/Posterior direction (A/P) and Medial/ Lateral direction $(\mathrm{M} / \mathrm{L})$ for Body Sway Deviations (BSD) and Body Sway Velocity (BSV). The Total Body Sway Area (TBSA) was also computed. All statistical tests were performed using SPSS 15. Descriptive statistics were used to report on mean, SD and median values of BS indicators, age, height, weight, BMI, daily physical activity (PA), dizziness, falls and social activity.

Data collected in terms of BSD and TBSA were considered as parametric; to assess the relation with age of these indicators and to compare means between the two groups for A/P BSD, M/L BSD and TBSA. Pearson's correlation coefficient and Independent Sample t-test were used.

Data collected in terms of BSV was treated as nonparametric data. Therefore to assess the relation with age of $\mathrm{A} / \mathrm{P}$ BSV, M/L BSV Spearman's rank correlation coefficient was used and to compare the two different groups, Mann-Whitney test was used.

To report on differences in TBSA, Ray charts (29) were used. Groups were adjusted for age and only $(\mathrm{N}=14)$ participants from each group - aged between 70 and 76 years - were selected for this analysis so that the differences observed can be attributed to differences in lifestyle rather than age itself. Mean values for TBSA were recalculated in terms of mean coordinates and projected onto $\mathrm{X}$ and $\mathrm{Y}$ axis for both $\mathrm{M} / \mathrm{L}$ and $\mathrm{A} / \mathrm{P}$ directions for both tests of quiet standing A\&B.
As indicators were divided into two groups parametric (BSD) and nonparametric (BSV), Scatter plots and correlations (Pearson's and Spearman's) were used to assess the relationship with calendar age $(\mathrm{N}=80)$. Finally to show changes in BSV with increasing age $(\mathrm{N}=80)$, a line chart was used and for better clarity, participants were divided into 7 age groups.

\section{Ethics}

All participants signed an informed consent form and this study obtained Ethical Approval.

\section{Results}

The Group from the Care Home was in average older, had higher BMI and showed higher BS values in all indicators of PS compared to the University of the Third Age group (Tab 1). Table 1 also shows differences in the level of self reported regular physical activity per day and experienced falls or episodes of dizziness. All participants in Care Home group had experienced at least 1 fall in the last five years. For the majority of these participants experienced more than 1 fall, and also felt dizzy more often than the University of the Third Age group. Time spent in social activity differed between the two groups. Participants in the Care Home group spent on average $45.4 \mathrm{~min} /$ week in a social activity whereas participants in Third Age University group have spent $86.3 \mathrm{~min}$ in a social activity per week.

The Independent Sample t-test confirmed statistically significant inter-group differences for BSD between the University of the Third Age group and the Care Home group A/P BSD $(p<0.01) ; \mathrm{M} / \mathrm{L} \mathrm{BSD}(\mathrm{p}<0.01)$ for both tests of

Tab. 1: Descriptive table showing differences between two groups (Care Home group and Third Age University group)

\begin{tabular}{|c|c|c|c|c|c|c|}
\hline & \multicolumn{3}{|c|}{ Care Home Group } & \multicolumn{3}{|c|}{ Third Age University group } \\
\hline & Min & Max & Mean (SD)/Median & Min & Max & Mean (SD)/Median \\
\hline \multicolumn{7}{|l|}{ Body Sway deviation $[\mathrm{mm}]$} \\
\hline $\mathrm{M} / \mathrm{L}$ & 1.1 & 6.7 & $2.7(0.9)$ & 0.6 & 4.2 & $1.9(0.9)$ \\
\hline $\mathrm{A} / \mathrm{P}$ & 1.1 & 6.1 & $2.8(0,9)$ & 0.8 & 2.8 & $1.8(0.5)$ \\
\hline \multicolumn{7}{|l|}{ Body Sway velocity $[\mathrm{mm} / \mathrm{sec}]$} \\
\hline $\mathrm{M} / \mathrm{L}$ & 9.5 & 25.5 & 11.4 & 9.3 & 11 & 9.9 \\
\hline $\mathrm{A} / \mathrm{P}$ & 9.4 & 21.2 & 11.9 & 9 & 11.6 & 9.7 \\
\hline Total Body Sway Area $\left[\mathrm{mm}^{2}\right]$ & 258 & 2507 & $728.3(344.1)$ & 217 & 804 & $409(135.1)$ \\
\hline AGE [years] & 71.6 & 96 & $82.9(6.1)$ & 57.5 & 75.8 & $66.5(5.2)$ \\
\hline Height $[\mathrm{m}]$ & 1.44 & 1.79 & $1.5(0.1)$ & 1.5 & 1.79 & $1.6(0.1)$ \\
\hline Weight $[\mathrm{kg}]$ & 49.8 & 106.9 & $68.7(6.1)$ & 57.2 & 96 & $68.9(9.8)$ \\
\hline BMI & 17.46 & 33 & $28.1(4.4)$ & 21.4 & 32.9 & $26.4(3.4)$ \\
\hline Regular PA [min/day] & 10 & 30 & 19.27 & 15 & 90 & 43.15 \\
\hline Dizzyness & - & - & $97.8 \%$ & - & - & $14.6 \%$ \\
\hline Falls & 1 & 5 & $100.0 \%$ & 1 & 1 & $1.2 \%$ \\
\hline Social Activity [min/week] & 20 & 60 & 45.4 & 45 & 90 & 86.3 \\
\hline
\end{tabular}



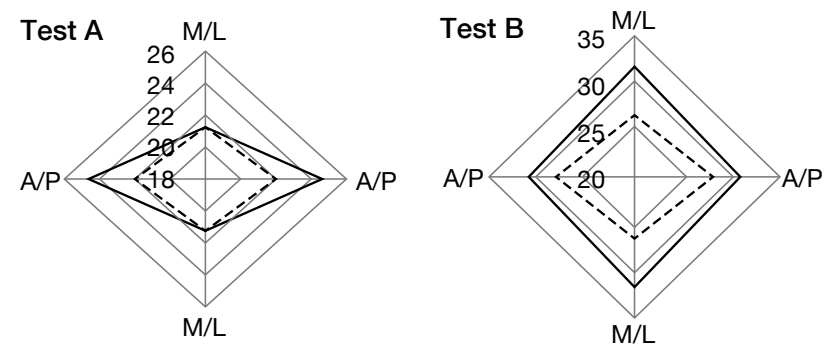

Fig. 1: Ray Charts for 2 groups (both aged 66-76 years) show Total Body Sway Area (TBSA) comparison between the Third Age University group (solid line) and the Care Home group (dash line) in Test A and in Test B

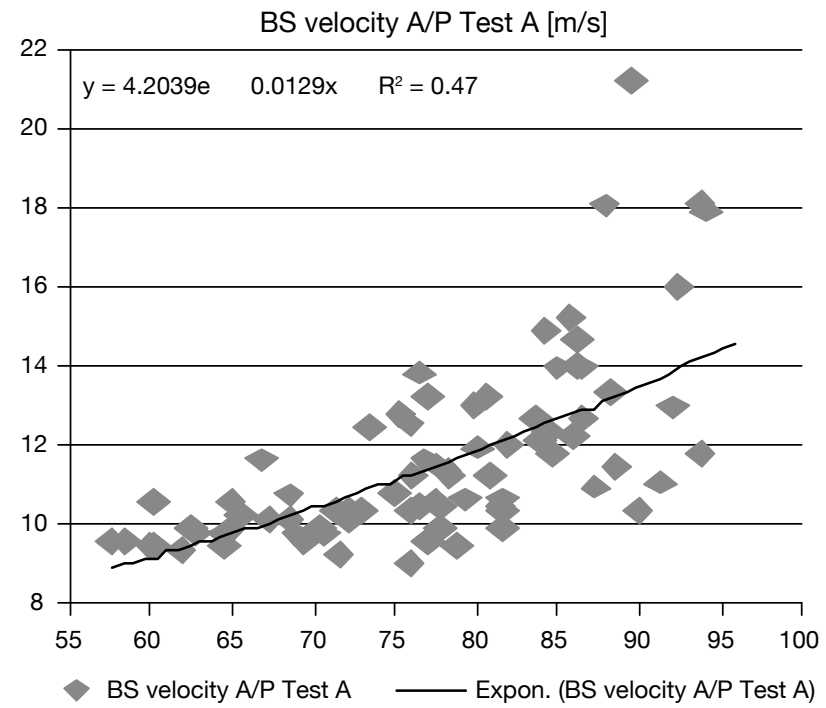

quiet standing (A\&B). The Mann-Whitney test confirmed statistically significant differences for BSV between the University of the Third Age group and the Care Home group A/P BSV $(p<0.01) ; \mathrm{M} / \mathrm{L} \mathrm{BSV}(\mathrm{p}<0.01)$ in both tests of quiet standing (A\&B).

Ray Charts (Fig. 1) show graphically differences in Total Body Sway Area (TBSA) when adjusted for the age difference between the two groups. The Care Home group had much larger TBSA in both Test A and Test B compared with the University of the Third Age group. For Test A mean values for the University of the Third Age group were: $\mathrm{M} / \mathrm{L}$ direction $21.26\left[\mathrm{~mm}^{2}\right], \mathrm{A} / \mathrm{P}$ direction $21.67\left[\mathrm{~mm}^{2}\right]$; mean values for the Care Home group were: $\mathrm{M} / \mathrm{L}$ direction $20.91\left[\mathrm{~mm}^{2}\right], \mathrm{A} / \mathrm{P}$ direction $24.58\left[\mathrm{~mm}^{2}\right]$. For Test B differ-

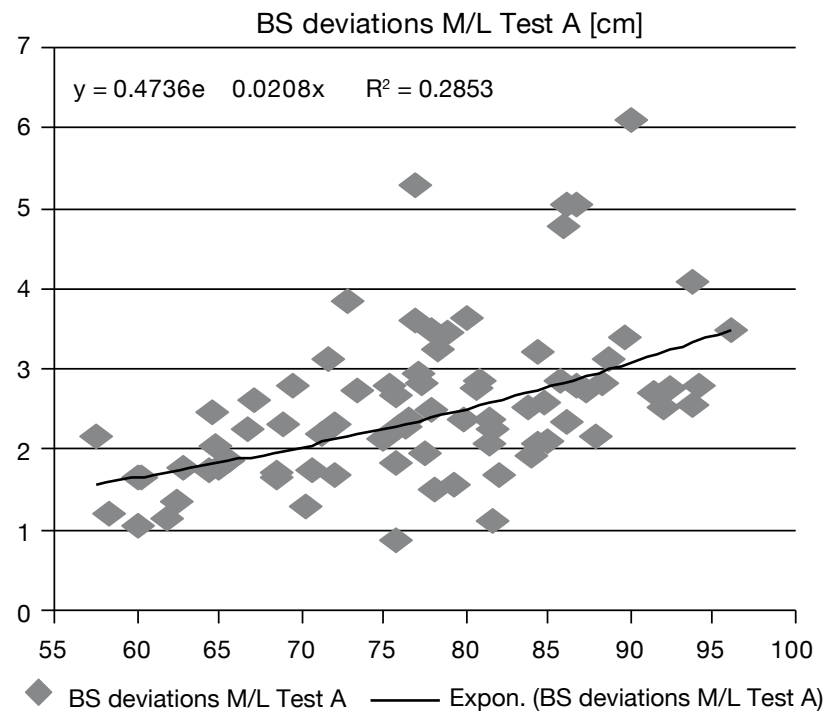

Fig. 2 and 3: Scatter plots - BSV and BSD deviations with increasing age

Tab. 2: Changes of BSV and of BSD with increasing age

\begin{tabular}{|c|c|c|c|c|c|c|c|c|}
\hline & & \multicolumn{7}{|c|}{$\overline{\text { Age }}$} \\
\hline Test A & $\begin{array}{l}\text { Spearman-Brown rank } \\
\text { correlation coefficient } r_{s}\end{array}$ & $60-64$ & $65-69$ & $70-74$ & $75-79$ & $80-84$ & 85-89 & $90+$ \\
\hline M/L BS velocity & $0.686(\mathrm{p}<0.001)$ & 9.60 & 10.0 & 10.3 & 10.7 & 11.1 & 12.5 & 13.3 \\
\hline A/P BS velocity & $0.727(\mathrm{p}<0.001)$ & 9.75 & 10.1 & 10.1 & 11.0 & 12.0 & 13.6 & 14.5 \\
\hline \multicolumn{9}{|l|}{ Test B } \\
\hline M/L BS velocity & $0.685(\mathrm{p}<0.001)$ & 10.7 & 11.6 & 12.30 & 12.4 & 12.7 & 16.6 & 19.2 \\
\hline A/P BS velocity & $0.682(\mathrm{p}<0.001)$ & 10.8 & 10.9 & 11.09 & 12.0 & 12.6 & 15.6 & 19.4 \\
\hline & & \multicolumn{7}{|c|}{ Age } \\
\hline Test A & Pearson correlation coefficient $r$ & $60-64$ & $65-69$ & $70-74$ & 75-79 & $80-84$ & 85-89 & $90+$ \\
\hline $\mathrm{M} / \mathrm{L}$ BS deviation & $0.433(\mathrm{p}<0.001)$ & 1.8 & 2.1 & 1.9 & 2.4 & 2.7 & 3.3 & 3.2 \\
\hline A/P BS deviation & $0.498(\mathrm{p}<0.001)$ & 1.7 & 2.2 & 2.5 & 2.5 & 2.4 & 3.3 & 3.4 \\
\hline \multicolumn{9}{|l|}{ Test B } \\
\hline $\mathrm{M} / \mathrm{L} \mathrm{BS}$ deviation & $0.545(\mathrm{p}<0.001)$ & 2.6 & 3.4 & 3.4 & 3.3 & 3.2 & 6.1 & 6.5 \\
\hline $\mathrm{A} / \mathrm{P} \mathrm{BS}$ deviation & $0.521(\mathrm{p}<0.001)$ & 2.5 & 3.5 & 4.1 & 3.2 & 3.4 & 5.1 & 5.8 \\
\hline
\end{tabular}




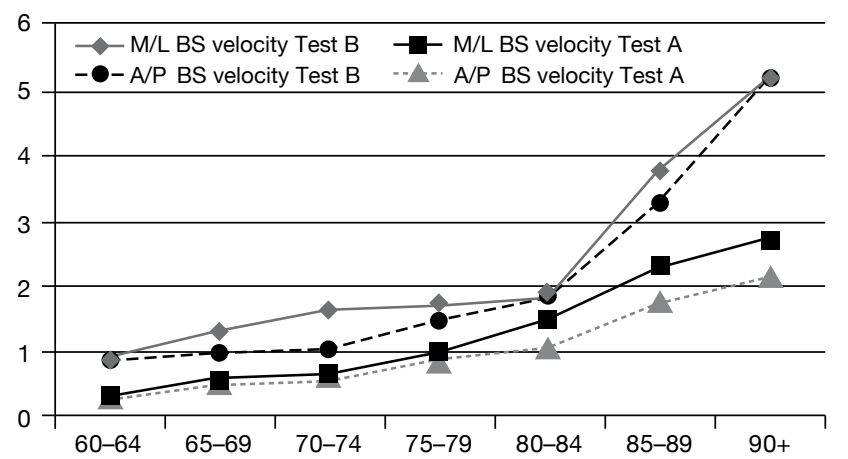

Fig. 4: Increasing BS velocity $[\mathrm{m} / \mathrm{s}]$ with increasing age [years]

ences in TBSA were much larger: A/P direction $28.3\left[\mathrm{~mm}^{2}\right]$ for the University of the Third Age group and $30.8\left[\mathrm{~mm}^{2}\right]$ for the Care Home group; and M/L direction $26.63\left[\mathrm{~mm}^{2}\right]$ for the University of the Third Age group and $31.55\left[\mathrm{~mm}^{2}\right]$ for the Care Home group.

Scatter plots and correlation coefficients show a stronger relationship for BSV $\left(\mathrm{r}^{2}=0.47\right)$ with calendar age than for BSD $\left(r^{2}=0.27\right)$ with calendar age; Figs 2 and 3. Table 2 shows the strength of the relationship with calendar age for BSD and BSV. The strongest correlation was found for $\mathrm{A} / \mathrm{P}$ BSV $0.727(p<0.001)$ in Test A, the weakest correlation was then found for M/L BSD $0.433(\mathrm{p}<0.001)$ in Test A as well.

The line charts further show how changes in BSV progress with increasing calendar age for tests A\&B (Fig. 4; Table 2). The correlation coefficients (Table 2) show how $\mathrm{BSV}$ increases with age in all participants. The BS velocity increases from $10.7[\mathrm{~m} / \mathrm{s}]$ in the youngest group (60-64) to $19.2[\mathrm{~m} / \mathrm{s}]$ in the oldest group over 90 . Fig. 4 shows that until the age of 80 BS velocity increases progressively although not steeply (confirmed by results in both tests A\&B, for $\mathrm{M} / \mathrm{L}$ $\mathrm{BSV}$ as well as for A/P BSV). From 80 onwards the BS velocity starts to increase, more markedly in Test B in both $\mathrm{M} / \mathrm{L} \mathrm{BSV}$ and A/P BSV. We have also noted that A/P BSV increases more than $\mathrm{M} / \mathrm{L}$ BSV in test A whereas both directions of BSV seem to increase equally for test B (Fig. 3).

\section{Discussion}

The aim was to observe and compare the Postural stability (PS), approximated by five Body Sway (BS) indicators, in two tests of quiet standing in two purposefully selected groups of volunteers, in relation to their adherence to social and physical activities. We had initially aimed to have both groups of a similar age but unfortunately the Care Home group of participants was at the baseline older. This made the comparison slightly difficult but for the Ray Charts this fact was accounted for and the two groups compared contained the same number of participants $(\mathrm{N}=14)$ who were within the same age range (70-76). This might imply that the difference our results show is associated with the different levels of physical and social activities. In this aspect our findings supports the findings of other authors (12, 15, $16,30)$ suggesting that PS worsens with increasing age and is associated with reduced amounts of physical and social activity.

However, our findings regarding the direction of BS are in contrast to Makki and Holliday's (23). They reported that Medial-Lateral (M/L) BS control was the most compromised in older people at risk of falls, and suggested M/L BS as the best indicator to predict future risk of falls. Our findings from the Ray charts indicate that in the Test A (easier test - where proprioception is not specifically challenged) the Residential Care Home Group ( $\mathrm{RCH}$ ) has shown worse results in body sway in $\mathrm{A} / \mathrm{P}$ direction in comparison to the University of the Third Age group (TAU) rather than in M/L direction as previously suggested by Makki and Holliday.

The importance of A/P body sway was also observed by Lucy et al. (25). They have reported higher body sway in $\mathrm{A} / \mathrm{P}$ direction in older adults. A possible explanation for the difference between $\mathrm{A} / \mathrm{P}$ and $\mathrm{M} / \mathrm{L}$ postural control due to the nature of bipedal standing, thus affording naturally better stability in M/L direction was suggested by Kang et al. (31). This could explain why the body sway in the A/P direction might be more easily compromised but further research is required to the mechanisms and differences in control of $\mathrm{A} / \mathrm{P}$ and $\mathrm{M} / \mathrm{L}$ body sway.

When comparing the relationship of Body sway velocity (BSV) and Body sway deviations (BSD) with calendar age, our results confirmed stronger relationship for BSV then for BSD. This finding is supported by Morasso and Schieppati (32) and Masani et al. (33) who suggested that actual postural control systems relies notably on velocity information. Masani et al. (33) further reported that the postural control systems during quiet stance might adopt a control strategy relying significantly on BS velocity information, and modulating the muscle activity in an anticipatory manner. Prieto et al. (34) reported the velocity of centre of pressure (COP) displacement as the only measure that identified age-related changes. All this leads us to support the idea that worsening of PS with ageing happens due to increasing BS velocity, which is, most probably, reflecting age-related decline in the neural processing. This idea was previously implied by Massion et al. (35) and Wilders et al. (36). They reported that BS velocity is affected by slow muscle activation times, which further affect the feedback and feed forward mechanisms and decrease the overall PS. High levels of muscle activity were described as a characteristic of age-related decline in PS, previously reported by Makki et al. (23). However, neither of them were clear whether such increase in muscle activity would preclude greater postural instability or increased muscle activity as a compensatory response.

Melzer et al. (37) suggested that a challenge to PS brings about an increased stiffness achieved through co-contraction of leg muscles as the compensatory response, supposedly decreasing the sway amplitude. In contrast Kang et al. 
(31) reported an increase in sway amplitude, together with increased muscular co-contraction, especially when performing dual tasks. Kang et al. (31) further suggested that increased co-contractions slow and hamper the ability to generate the corrective reactions to environmental perturbations (slips and trips) leading to falls. This could worsen with a feeling of insecurity and/or post fall anxiety, known to affect especially older fallers (38). The feeling of insecurity could increase muscle activity, reported by Kang et al. (31) as co-contraction and worsen already slowed postural reaction to perturbations, having an overall destabilizing effect for which the body systems cannot (due to age-related changes) compensate. For all the above reasons we support the idea that BSV increases, reported also in our findings, represent a substantial danger to the overall postural stability and that BS velocity, once extracted from platform stabilometry measurements, and might further serve as an indicator of progressive age-related changes in physical functioning.

This further leads us to reflect on how to account for BSV age-related changes when designing a corrective therapy. From the literature we know that corrective therapy usually focuses on BSD by encouraging yoga, Pilates, muscle strengthening and more recently balance training (24); and the focus on BSD might be the reason why such corrective therapies were not evaluated as very effective. Based on our results we would suggest evaluations targeting rather BSV when measuring effects of intervention/exercise.

Due to age-related changes in BSV, reflecting to a greater extent changes in nerve conduction velocity and accuracy, as discussed above, we may need a different exercise. Several authors (Vojta, Vele) have suggested this exercise focusing more on joint flexibility and muscle synergies, while stimulating inborn locomotor patterns $(39,40)$. These were described by Vojta, Vele, Panjabi (39-41) and linked with correct breathing patterns (39). Such exercising could have rather a 'stimulating and reassuring' effect that might help to compensate for stiffness induced co-contractions and support the ability to generate corrective reactions to environmental perturbations, especially in fallers. Interventions targeting joint flexibility and muscle strengthening were recently introduced by Mazzeo et al. (42), but without encouraging findings, Mazzeo (42) focused on root joints only. When spine flexibility and strengthening exercising were added, Danneels et al. (43) and Hides et al. (44), combining stabilization training together with dynamic static resistance, reported more encouraging findings. In addition better spine flexibility was found to improve functional reach, decrease functional limitations and improve balance control in the elderly $(24,45-47)$. To demonstrate better these mechanisms further research is needed.

Finally we have also noted that BS velocity starts to change more steeply around the age of 80 (Fig. 4 Line chart). Our results have shown this trend in both tests of quiet standing. Results from more difficult tests show an even steeper increase in BS velocity from age of 80 onwards. However further research is also needed to find more general patterns.

\section{Limitations of the study}

Participants and Care Homes were not randomly chosen this might be a limiting factor in terms of the generalizability of our results. Also we would like to add that in this study we were comparing older adults with different levels of physical activity. We have tried to make both samples comparable as to their function, mobility and ability to complete the testing without help (see inclusion and exclusion criteria) but we are aware that there are still few limitations that need addressing. One limitation arises from different mean age of the groups. On one hand this has been addressed in methods in participants section (inclusion and exclusion criteria) and data analysis section (where for Ray Charts we have adjusted for age so both samples are in the same age range). On the other hand as one of the aims of this observational study was looking onto how PS indicators (BSV and BSD) change with increasing age we think that differences in mean age between he groups might not be that limiting after all. Another limitation might be that even if we reduced the number of drugs being taken by 3 , there still may be some drug interactions we are not aware of which of course is, to some extent, limiting results of this study. On the other hand there were few authors in the past (i.e. Stelmach) that argued for less tight exclusion criteria as it might be altering the picture of the elderly population.

Another limitation might be that platform stabilometry as a method is not very sensitive to changes in motivation, moods or emotions, as these are difficult to assess in real time measurement. Also questionnaires assessing falls, dizziness, levels of PA and social activity in this study were used only to interpret results. Further research would be focused on using more precisely coded levels of social and physical activity and on exercising involving spine flexibility.

\section{Conclusions}

Postural stability (PS) has been assessed using five various indicators in two different groups of volunteers (a Third Age University group and a Residential Care Home group). Levels of usual physical and social activities were also assessed in all participants. PS in the Residential Care Home group was significantly worse than the results of the Third Age University group. This difference, we suggest, can be attributed not only to age-related changes but also to reduced physical and social activity in the Care Home group. This study has shown that it is beneficial to divide PS indicators into BS deviation and BS velocity and observe age-related changes affecting BS Deviation (BSD) and BS Velocity (BSV) in different ways. Our results indicate that the age-dependent indicator is BSV rather than BSD, and that BSV contributes to overall PS more than BSD, which is in agreement with previous studies. Therefore we suggest that BSV needs to be accounted for when designing the physical activity to prevent falls in the elderly. 


\section{Acknowledgements}

I would like to thank my former colleagues Dr. Jana Tumova, Dr. Hana Novakova, and Dr. Frantisek Zahalka from the Faculty of Physical Education and Sport Science, Charles University Prague, for their extensive help with data collection. This study was funded through Charles University Internal Grant Agency in 2006 and Charles University Internal Grant Agency in 2007.

\section{References}

1. Spirduso WW, Francis KL, MacRae PG. Physical dimensions of aging. Human Kinetics Publishers, 2005.

2. Lord SR, Sambrook PN, Gilbert C, et al. Postural stability, falls and fractures in the elderly: results from the Dubbo Osteoporosis Epidemiology Study. Med J Aust 1994; 160(11): 684

3. Dhesi JK, Jackson SHD, Bearne LM, Moniz C, Hurley MV, Swift CG, et al. Vitamin D supplementation improves neuromuscular function in older people who fall. Age Ageing 2004; 33(6): 589.

4. Heinrich S, Rapp K, Rissmann U, Becker C, König HH. Cost of falls in old age: a systematic review. Osteoporosis Int 2010; 21(6): 891-902.

5. Rubenstein LZ. Falls in older people: epidemiology, risk factors and strategies for prevention. Age Ageing 2006; 35(suppl 2): ii37.

6. Gillespie LD, Robertson MC, Gillespie WJ, et al. Interventions for preventing falls in older people living in the community. Cochrane Database Syst Rev 2009; 2 .

7. Howe T, Rochester L, Jackson A, Banks P, Blair V. Exercise for improving balance in older people (Review). 2008.

8. Kalvach Z. Geriatrie a gerontologie. Grada, 2004

9. Skelton DA. Effects of physical activity on postural stability. Age Ageing 2001; 30(suppl 4): 33-39.

10. Coggan AR, Abduljalil AM, Swanson SC, Earle MS, Farris JW, Mendenhall LA, et al. Muscle metabolism during exercise in young and older untrained and endurance-trained men. J Appl Physiol 1993; 75(5): 2125-2133.

11. Kirkendall DT, Garrett WE. The effects of aging and training on skeletal muscle. Am J Sports Med 1998; 26(4): 598.

12. Winter DA, Prince F, Frank J, Powell C, Zabjek KF. Unified theory regarding A/P and $\mathrm{M} / \mathrm{L}$ balance in quiet stance. J Neurophysiol 1996; 75(6): 2334-2343.

13. Cumming RG, Salkeld G, Thomas M, Szonyi G. Prospective study of the impact of fear of falling on activities of daily living, SF-36 scores, and nursing home admission. The Journals of Gerontology Series A: Biological Sciences and Medical Sciences 2000; 55(5): M299.

14. Winter DA. ABC (anatomy, biomechanics and control) of balance during standing and walking. Waterloo Biomechanics, 1995.

15. Winter DA, Patla AE, Prince F, Ishac M, Gielo-Perczak K. Stiffness control of balance in quiet standing. J Neurophysiol 1998; 80(3): 1211.

16. Rocchi L, Chiari L, Cappello A. Feature selection of stabilometric parameters based on principal component analysis. Medical and Biological Engineering and Computing 2004; 42(1): 71-79.

17. Chiari L, Rocchi L, Cappello A. Stabilometric parameters are affected by anthropometry and foot placement. Clin Biomech 2002; 17(9): 666-677.

18. Prince F, Winter D, Archer S. Assessment of postural control during quiet stance with different foot configuration. Gait and posture 1995; 3(2): 110-110.

19. Suchomel T. Stabilita v pohybovém systému a hluboký stabilizační systém-podstata a klinická východiska. Rehabilitace a fyzikální lékařství 2006; 13(3): 112-124.

20. Suchomel T, Lisický D. Progresivní dynamická stabilizace bederní páteře. Rehabilitace a fyzikální lékařství 2004: 128-136.

21. Lafond D, Corriveau H, Hebert R, Prince F. Intrasession reliability of center of pressure measures of postural steadiness in healthy elderly people1. Arch Phys Med Rehabil 2004; 85(6): 896-901.

22. Jančová $J$, Tošnerová $V$. Use of stabilometric platform and evaluation of methods for further measurement - a Pilot study. Acta Medica (Hradec Králové) 2007; 50(2): 139-143.

23. Maki BE, Holliday PJ, Topper AK. A prospective study of postural balance and risk of falling in an ambulatory and independent elderly population. J Gerontol 1994; 49(2): M72.

24. Sherrington C, Whitney JC, Lord SR, Herbert RD, Cumming RG, Close JCT. Effective exercise for the prevention of falls: a systematic review and meta-analysis. J Am Geriatr Soc 2008; 56(12): 2234-2243.

25. Lucy S, Hayes K. Postural sway profiles: normal subjects and subjects with cerebellar ataxia. Physiother Can 1985; 37: 140-148.

26. Tumova J. Overeni vlivu pohyboveho programu na zlepseni stability u starsich osob pomoci posturografie - PhD Thesis. FTVS Charles University Prague 2003

27. Jancova J. Measuring the balance control system - review. Acta Medica (Hradec Kralove) 2008; 51(3): 129-137.

28. Boswart J. Manual for Kistler Platform, Prague. 1990.

29. Novakova H. Problematika vyuziti posturografie v kineziologii. Rehabilitace a fyzikalni lekarstvi 2001; 2(8): 65-69.

30. Tinetti ME, Williams CS. The effect of falls and fall injuries on functioning in community-dwelling older persons. The Journals of Gerontology Series A: Biological Sciences and Medical Sciences 1998; 53(2): M112.

31. Kang HG, Lipsitz LA. Stiffness Control of Balance During Quiet Standing and Dual Task in Older Adults: The MOBILIZE Boston Study. J Neurophysiol 2010; 104(6): 3510.

32. Morasso PG, Schieppati M. Can muscle stiffness alone stabilize upright standing? J Neurophysiol 1999; 82(3): 1622-1626.

33. Masani K, Popovic MR, Nakazawa K, Kouzaki M, Nozaki D. Importance of body sway velocity information in controlling ankle extensor activities during quiet stance. J Neurophysiol 2003; 90(6): 3774.

34. Prieto TE, Myklebust J, Hoffmann R, Lovett E, Myklebust B. Measures of postural steadiness: differences between healthy young and elderly adults. Biomedical Engineering, IEEE Transactions on 1996; 43(9): 956-966.

35. Massion J, Dufosse M. Coordination between posture and movement: why and how? Physiology 1988; 3(3): 88-93.

36. Wilder DG, Aleksiev AR, Magnusson ML, Pope MH, Spratt KF, Goel VK. Muscular response to sudden load: a tool to evaluate fatigue and rehabilitation. Spine 1996; 21(22): 2628-2639.

37. Melzer I, Benjuya N, Kaplanski J. Age-related changes of postural control: effect of cognitive tasks. Gerontology 2001; 47(4): 189-194.

38. Legters K. Fear of falling. Phys Ther 2002; 82(3): 264-272.

39. Vojta V, Peters A. Das vojta-prinzip: muskelspiele in reflexfortbewegung und motorischer ontogenese. Springer Verlag, 2007.

40. Véle F. Kineziologie pro klinickou praxi. Grada Publishing, 1997.

41. Panjabi MM, White AA. Biomechanics in the musculoskeletal system. Churchill Livingstone Philadelphia, 2001

42. Mazzeo RS, Cavanagh P, Evans WJ, et al. ACSM position stand: exercise and physical activity for older adults. Medicine \& Science in Sports \& Exercise 1998; 30(6): 992.

43. Danneels L, Vanderstraeten G, Cambier D, et al. Effects of three different training modalities on the cross sectional area of the lumbar multifidus muscle in patients with chronic low back pain. Br J Sports Med 2001; 35(3): 186-191.

44. Hides J, Gilmore C, Stanton W, Bohlscheid E. Multifidus size and symmetry among chronic LBP and healthy asymptomatic subjects. Man Ther 2008; 13(1) $43-49$.

45. Schenkman M, Morey M, Kuchibhatla M. Spinal flexibility and balance contro among community-dwelling adults with and without Parkinson's disease. The Journals of Gerontology Series A: Biological Sciences and Medical Sciences 2000; 55(8): M441.

46. Iversen MD, Kale MK, Sullivan Jr JT. Pilot case control study of postural sway and balance performance in aging adults with degenerative lumbar spinal stenosis. Journal of Geriatric Physical Therapy 2009; 32(1): 15.

47. Lynch SM, Leahy P, Barker SP. Reliability of measurements obtained with a modified functional reach test in subjects with spinal cord injury. Phys Ther 1998; 78(2): $128-133$.

Received: 23/07/2012

Accepted in revised form: 20/09/2013

\section{Corresponding author:}

Jitka Jančová Všetečková, School of Health Sciences, City University London, Northampton Square, London EC1V OHB, United Kingdom; e-mail: Jitka.Jancova.1@city.ac.uk 